\title{
Trend analysis for evaluating the consistency of Terra MODIS and SPOT VGT NDVI time series products in China
}

\author{
Youzhi AN ${ }^{1}$, Wei GAO ${ }^{1,2}$, Zhiqiang GAO $(\bowtie)^{2,3}$, Chaoshun LIU ${ }^{1}$, Runhe SHI ${ }^{1}$ \\ 1 Key Laboratory of Geographic Information Science, Ministry of Education, East China Normal University, Joint Laboratory for Environmental \\ Remote Sensing and Data Assimilation, ECNU \& CEODE, CAS, Shanghai 200062, China \\ 2 Natural Resource Ecology Laboratory, Colorado State University, Fort Collins CO 80523, USA \\ 3 Yantai Institute of Coastal Zone Research, Chinese Academy of Sciences, Yantai 264003, China
}

(C) Higher Education Press and Springer-Verlag Berlin Heidelberg 2014

\begin{abstract}
The Normalized Difference Vegetation Index (NDVI) is an important vegetation greenness indicator. Compared to the AVHRR GIMMS NDVI data, the availability of two datasets with $1 \mathrm{~km}$ spatial resolution, i.e., Terra MODIS (MOD13A3) monthly composite and SPOT Vegetation (VGT) 10-day composite NDVI, extends the application dimensions at spatial and temporal scales. An overlapping period of 12 years between the datasets now makes it possible to investigate the consistency of the two datasets. Linear regression trend analysis was performed to compare the two datasets in this study. The results show greater consistency in regression slopes in the semi-arid regions of northern China. Alternatively, the results show only slight changes in the Terra MODIS NDVI regression slope in most areas of southern China whereas the SPOT VGT NDVI shows positive changes over a large area. The corresponding regression slope values between Terra MODIS and SPOT VGT NDVI datasets from the linear fit had a fair agreement in the spatial dimension. However, larger positive and negative differences were observed at the junction of the three regions (East China, Central China, and North China). These differences can be partially explained by the positive standard deviation differences distributed over a large area at the junction of these three regions. This study demonstrated that Terra MODIS and SPOT VGT NDVI have a relatively robust basis for characterizing vegetation changes in annual NDVI in most of the semi-arid and arid regions in northern China.
\end{abstract}

Keywords Terra MODIS NDVI, SPOT VGT NDVI, trend analysis, correlation analysis

Received June 20, 2013; accepted November 20, 2013

E-mail: gaoland@gmail.com

\section{Introduction}

Remote sensing is currently the most commonly used method of data collection for characterizing global vegetation dynamics. In particular, the Normalized Difference Vegetation Index (NDVI) has been recognized as an important measure for evaluating regional and local vegetation changes since the early 1980s (Tucker, 1979). Until now, NDVI datasets have been used for a variety of purposes and at scales ranging from individual watersheds to the global scale. NDVI data can be used to assess vegetation trends (Tucker et al., 2001), vegetation and climate relevance (Lucht et al., 2002; Hu et al., 2011), phenological change (Stöckli and Vidale, 2004; Zhang et al., 2006; Heumann et al., 2007), ecological response to environmental change (Pettorelli et al., 2005), leaf area index (LAI; Wang et al., 2005), vegetation cover (Bartalev et al., 2003), desertification and land degradation (Symeonakis and Drake, 2004; Bai et al., 2008), ecosystem disturbances (such as wildfires, hurricanes, insect outbreaks) (Mildrexler et al., 2009), and Net Primary Production (NPP) (Nemani et al., 2003; Hickler et al., 2005). Although the NDVI easily becomes saturated when viewing forests and other areas with large amounts of chlorophyll (Sellers, 1985; Gao et al., 2000), it is still the most widely used vegetation index for monitoring vegetation over large areas or large timescales.

The Moderate Resolution Imaging Spectroradiometers (MODIS) onboard the Earth Observation System (EOS) Terra and Aqua satellites were launched on December 1999 and May 2002, respectively. They can be used to monitor the biophysical variables of the Earth. The MODIS spatial resolutions were $1 \mathrm{~km}$ (29 bands), $500 \mathrm{~m}$ (5 bands), and $250 \mathrm{~m}$ ( 2 bands) with a one-day temporal resolution. Thus, MODIS data are advantageous in a wide range of scientific research. However, some issues that 
must be considered when using MODIS data include greater spatial inter-pixel correlation in the cross-track direction than in the along-track direction due to its whiskbroom scanning system (Schowengerdt, 2007), and the so-called "bow-tie" effect caused by consecutive MODIS scan lines that overlap when the view zenith angles (VZA) are not $0^{\circ}$ (Wolfe et al., 2002). The vegetation index data have been corrected for molecular scattering, ozone absorption, and aerosols, and have been adjusted to nadir and standard sun angles with the use of bidirectional reflectance distribution function (BRDF) models (http://vip.arizona.edu/MODIS_UsersGuide.php).

The Satellite Pour l'Observation de la Terre (SPOT) family of satellites has provided remarkable observations of the Earth from SPOT 1-6 since 1986. The SPOT NDVI datasets are composed of vegetation (VGT) data from the SPOT 4 and the SPOT 5 satellite platforms launched in March 1998 and May 2002, respectively. These satellites were to be used specifically for monitoring vegetation cover and properties. The SPOT VGT 10-day synthesis NDVI (S10) data are available at a resolution of approximately $1 \mathrm{~km} \times 1 \mathrm{~km}$. Currently, NDVI data from the SPOT-VEGETATION (VGT1 and 2) sensors are widely used for many operational applications. The SPOT NDVI was derived from the red bands with electromagnetic wavelengths of $0.61-0.68 \mu \mathrm{m}$ and near infrared bands with wavelengths of $0.78-0.89 \mu \mathrm{m}$, unlike the MODIS NDVI data, which were derived from red $(0.62-0.67 \mu \mathrm{m})$ and near infrared bands $(0.84-0.88 \mu \mathrm{m})$. Atmospheric effects were performed using the simplified method for atmospheric corrections model (SMAC) (Rahman and Dedieu, 1994). Other adverse parameters, such as the sensor's sensitivity drift, molecular scattering, aerosol scattering, water vapor, ozone, and other gas absorption, were corrected to obtain non-cloudy and non-snowy data.

A feasibility analysis was necessary to compare the NDVI products from MODIS and SPOT imagery. To detect vegetation change, NDVI products are usually derived from the Advanced Very High Resolution Radiometer (AVHRR), SPOT, or MODIS. Compared to the coarse-resolution GIMMS NDVI, with an 8-km resolution, the MODIS and SPOT NDVI offer an improved and finer combination of spatial $(1 \mathrm{~km})$ and spectral resolutions with a high temporal frequency. Time-series data were derived from medium resolution satellite images, such as MODIS and SPOT VGT products that can be used to analyze the vegetation dynamics over long time periods (MODIS dates back to 2000 and SPOT to 1998). With 12 years of data for both the MODIS NDVI (2000-2011) and SPOT NDVI (1998-2011), a reliability evaluation of MODIS and SPOT NDVI trends for this time-span can be performed. NDVI datasets for approximately 14 years (1998-2011) from the SPOT satellite could be correlated with the Terra MODIS data to provide a long-term data profile at a $1-\mathrm{km}$ spatial scale. As their availability and accessibility increase, the multi-sensor NDVI products will likely be an improvement to the GIMMS NDVI product for monitoring vegetation conditions (Huete et al., 2002; Maisongrande et al., 2004). Therefore, it is necessary to evaluate the consistency of the two data products acquired over the same observational time periods (from 2000 to 2011). In previous studies, two datasets were compared regionally (Mao et al., 2012) and nationally (Song et al., 2010). In addition, the datasets were compared at both continental and global scales (Fensholt et al., 2006; Beck et al., 2011; Fensholt and Proud, 2012). However, relatively few studies have been conducted to assess the spatial consistency of a $1-\mathrm{km}$ resolution MODIS and SPOT NDVI dataset covering China.

This study assesses and compares the capability of the time-series MODIS and SPOT imagery to analyze the trend consistency of China. This study mainly focuses on (i) the trend and correlation analysis of MODIS and SPOT NDVI using the overlapping annually integrated NDVI datasets from 2000 to 2011, and (ii) the annual difference between MODIS and SPOT NDVI via the regression slope, correlation coefficient, and standard deviation.

\section{Data and methods}

\subsection{Terra MODIS monthly composite NDVI data}

The NDVI satellite dataset used in this study was from the MODIS instrument onboard the Terra satellite. We used monthly composite data at a 1-km resolution (MOD13A3, L3 Global $1 \mathrm{~km}$, and collection 5) from 2000 to 2011. The 23 tiles of MOD13A3 coverage for China were accessed from the USGS Land Processes Distributed Active Archive Center (LP DAAC, http://ladsweb.nascom.nasa. gov/data/search.html). These tiles were derived from the 16-day 1-km MODIS NDVI (MOD13A2) output, which was temporally aggregated using a weighted average to create a calendar-month composite of the data (http://vip. arizona.edu/MODIS_UsersGuide.php). The MOD13A3 vegetation product contains a data quality assessment product (QA data) that contains information on the overall usefulness, the pixel reliability, and the cloud conditions on a per-pixel basis. This product has a ranked summary quality layer (SDS), which contains ranked values that describe the overall pixel quality. Rank keys have five classes. The flags $-1,0,1,2$, and 3 denote data that are "Fill/No data (Not processed)," "Good data (Use with confidence)," "Marginal data (Useful, but look at other QA information)," "Snow/Ice (Target covered with snow/ice)," and "Cloudy (Target not visible, covered with cloud)," respectively. High quality data were defined as data with a Rank key flag of 0 , and all other combinations were classified as poor quality data. More specific explanations of the MOD13A3 VI pixel reliability can be found in the MODIS User's Guide (http://vip.arizona.edu/MODIS_UsersGuide.php). 


\subsection{SPOT VGT 10-day composite NDVI}

In this study, 1-km resolution SPOT NDVI data in the Plate Carree (Equirectangular) geographic projection were obtained from the Free VEGETATION Products website (http://free.vgt.vito.be/). The 10-day composite NDVI data acquired from 2000 to 2011 were composed of daily data from two observation instruments (VEGETATION 1 and VEGETATION 2) onboard the SPOT 4 and SPOT 5 satellites, respectively. Ten-day NDVI image composites (S10) were computed from all of the passes for each location acquired during 10-day periods using the maximum value composite (MVC) method (http://www.spotvegetation.com/pages/VegetationSystem/products.htm). The data quality information was obtained from the Status Map (SM) layer that included some of the potential problems observed for the reflectance of each band. The SM binary screening approach was applied to each SPOT pixel that was included in the correlation analyses. The binary code requirement for the overall usefulness combination information was 11111000 . The "Bit NR 0," "Bit NR 1," and "Bit NR 2" SM values must be equal to 0 (meaning clear and with no ice or snow), and the "Bit NR 3-7" SM values must equal 1 (good radiometric quality). More specific explanations of Status Map for the SPOT VGT NDVI product can be found on the data acquisition website (http://free.vgt.vito.be/vgtformat.php).

\subsection{Land cover data}

Land cover data (MCD12Q1-IGBP, 2009) are shown in Fig. 1 as a reference to further analyze the MODIS and SPOT NDVI trends for major land cover classes. Additionally, land cover data with a 500-m resolution were resampled to create a geographic type at an approximate resolution of $1 \mathrm{~km} \times 1 \mathrm{~km}$ to match with MODIS and SPOT NDVI.

\subsection{Data post-processing and methodology}

All MODIS images were reprojected to the WGS-84 coordinate system using the nearest-neighbor resampling method by the MODIS Reprojection Tool V4.0 (MRT). Additionally, the VGT Extract tool was used to georeference the SPOT NDVI data to the same coordinate system as the MODIS products. The original 10-day SPOT NDVI composite data covering the period from January 2000 to December 2011 were aggregated to monthly data using the maximum value composite (MVC) method. The MVC method was used to select the observation with the highest NDVI values to represent the composite period (10 days) (Huete et al., 2002). The same method was used to produce the annual composition of MODIS and SPOT NDVI from monthly images. Because MODIS data were not available for the first month in the observation year

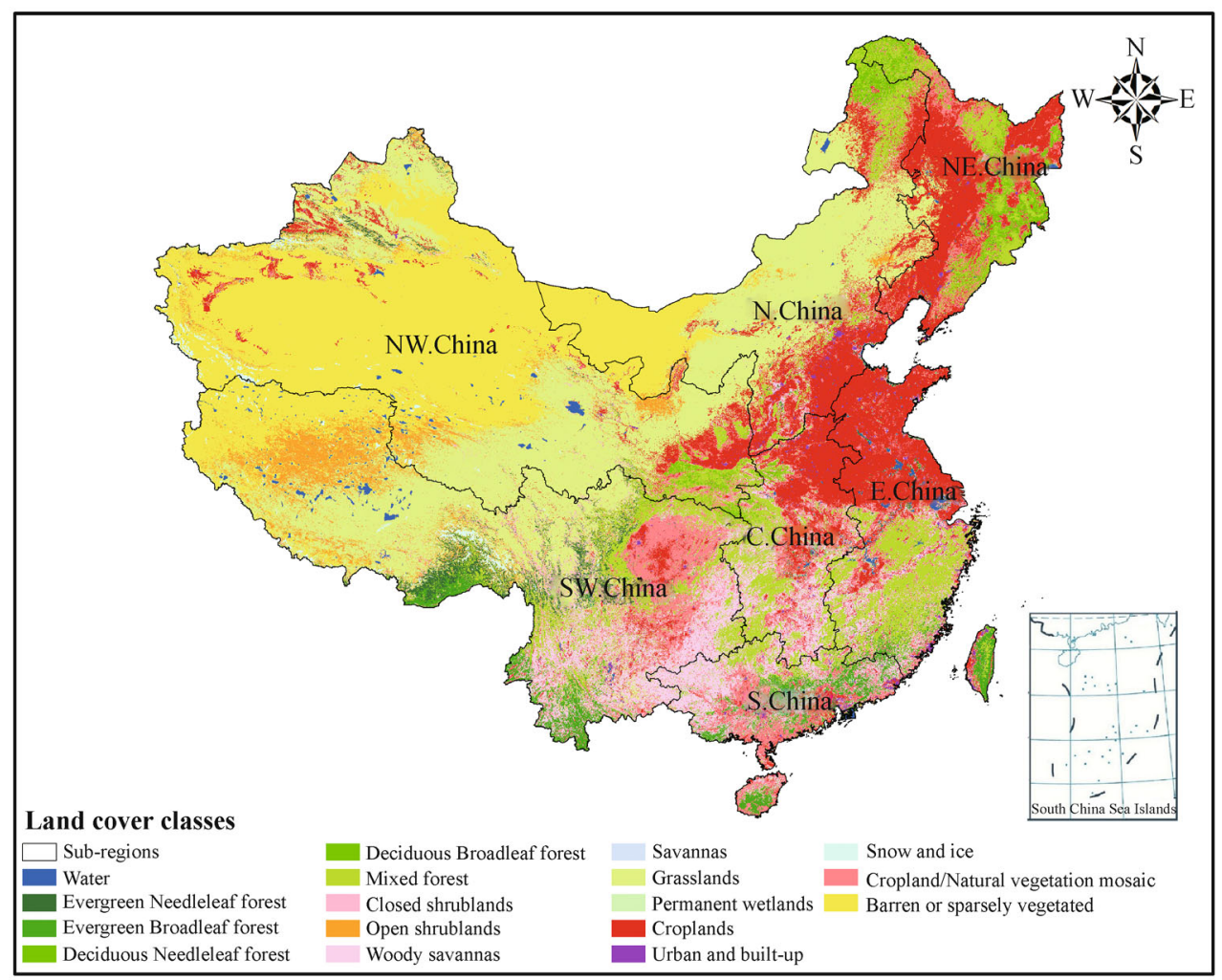

Fig. 1 Spatial distribution of the seven sub-regions and MODIS-based land cover classes in China. Where, East China (E.China), Central China (C.China), Northeast China (NE.China), North China (N.China), Northwest China (NW.China), South China (S.China), Southwest China (SW.China). 
2000, the average values for the first month from 20012011 were used to fill in the missing data. The per-pixel QA information for both the MODIS and SPOT products was used to remove the poor quality NDVI data (data that were either influenced by cloud cover or by snow and ice). A simple temporal filter was applied to gap-fill the missing MODIS and SPOT data (Xiao et al., 2003; Fensholt et al., 2006, 2009). Additionally, a Savitsky-Golay filter was used to smooth the MODIS and SPOT data (Savitzky and Golay, 1964).

The linear regression model was used to assess the correspondence in spatio-temporal trends between the NDVI from MODIS and SPOT and the strength of the correlation coefficient $(r)$ for the 12-year time series of annual observations that passed the QA screening. The linear regression model is a simple, yet robust way to analyze long-term trends in NDVI time series. With time as the independent variable and NDVI as the dependent variable, the linear regression model was used to examine temporal trends between the two datasets. The outputs of the trend analysis were visually represented by mapping the correlation coefficient ( $r$ values) and the regression slope values to represent the strength and magnitude of the calculated trends. The resulting slope values and $r$ values on a pixel level could easily be compared because they were calculated using the same model. The non-parametric Mann-Kendall (MK) test has been commonly applied to time series data for NDVI trend analysis (Fensholt and Proud, 2012); it was therefore used in this study. For the confidence interval $\alpha=0.05$, a positive slope $(z \geqslant 1.96)$ represents a significant increase in NDVI for the period $2000-2011$, while a negative slope $(z \leqslant-1.96)$ indicates a significant decrease.

To further analyze the time series trend analysis consistency between MODIS and SPOT NDVI in different sub-regions, China was divided into seven zones (Fig. 1).

\section{Results}

\subsection{MODIS and SPOT NDVI trend analysis}

As described above, the temporal filter was applied to fill in data gaps caused by cloud influence over the 12 years. A Savitsky-Golay filter was used to smooth the MODIS and SPOT data. Regression slope values from the MODIS and SPOT annual NDVI data from 2000-2011 are shown in Figs. 2(a) and 2(b). An annual NDVI standard deviation (SD) of less than 0.02 (e.g., desert areas) was masked out to reduce the uncertainty in the vegetation index estimation. Trend statistics for pixel-to-pixel comparisons with significant positive/negative regression slopes are reported for seven regions (total number of pixels and percentages) (Table 1). Trend statistics of the MODIS and SPOT NDVI analyses for the major land cover classes are shown in Table 2. Scatter plots (density distribution plots) of the major calculated trends (regression slope values) from annually integrated observations of MODIS and SPOT are subdivided into seven sub-regions (Fig. 3) to investigate the consistency of the regression slope values at the regional scale.

\subsection{Comparison of MODIS and SPOT NDVI}

Observations that passed the QA screening and that had an annual NDVI SD of more than 0.02 at a $95 \%$ significance level are shown in color. The corresponding regression slopes from the MODIS/SPOT NDVI linear correlations are shown in Figs. 4(a) and 4(b). Trend statistics of the regression slope values by the MODIS/SPOT NDVI analyses for the major land cover classes are shown in Table 3. MODIS/SPOT linear trend regression slope values (MODIS NDVI being the independent variable and SPOT NDVI being the dependent variable) were plotted against the MODIS/SPOT $r$ values as density plots on a regional scale (Fig. 5). Correlations between the spatial distributions in the regression slopes, $r$-values, and annual SDs between MODIS and SPOT NDVI were determined (Figs. 6(a), 6(b), and 6(c)).

\section{Discussion}

\subsection{Trends comparison in annual MODIS and SPOT NDVI}

Both MODIS and SPOT NDVI pixels exhibit linearly increasing and decreasing trends over the 12-year period. The statistical analysis trends of total pixels $(n)$ for MODIS and SPOT NDVI (SD >0.02) were not significant, but the MODIS and SPOT NDVI positive and negative regression slopes $(n)$ were significant at a confidence level of $95 \%$. In areas of NDVI where SD was greater than 0.02 , a significant trend was found for $31.7 \%$ of the MODIS NDVI pixels in China (25.4\% positive and $6.3 \%$ negative). In contrast, $55.5 \%$ of pixels in SPOT NDVI data showed a significant trend (53.2\% positive and $2.3 \%$ negative).

Both the MODIS and SPOT NDVI datasets showed agreement in greening trends in some areas of Northeast China (Songnen Plain), North China (Loess Plateau), and Central China (Henan Province). However, the results also show significant differences from the three regions $(57.7 \%$, $21.0 \%$, and $39.0 \%$, respectively).

On a regional scale, both NDVI datasets generally showed good agreement in areas with significant negative trends in North China (Bohai Rim and Inner Mongolia), East China (Yangtze River Delta), South China (Pearl River Delta), and Southwest China (Sichuan Basin). However, relatively small differences were also observed in each region $(4.1 \%, 1.9 \%, 4.3 \%$, and $3.9 \%$, respectively). Comparisons between the SPOT-derived regression slope values and the MODIS datasets show decreased trends, although positive changes were shown in large areas of 

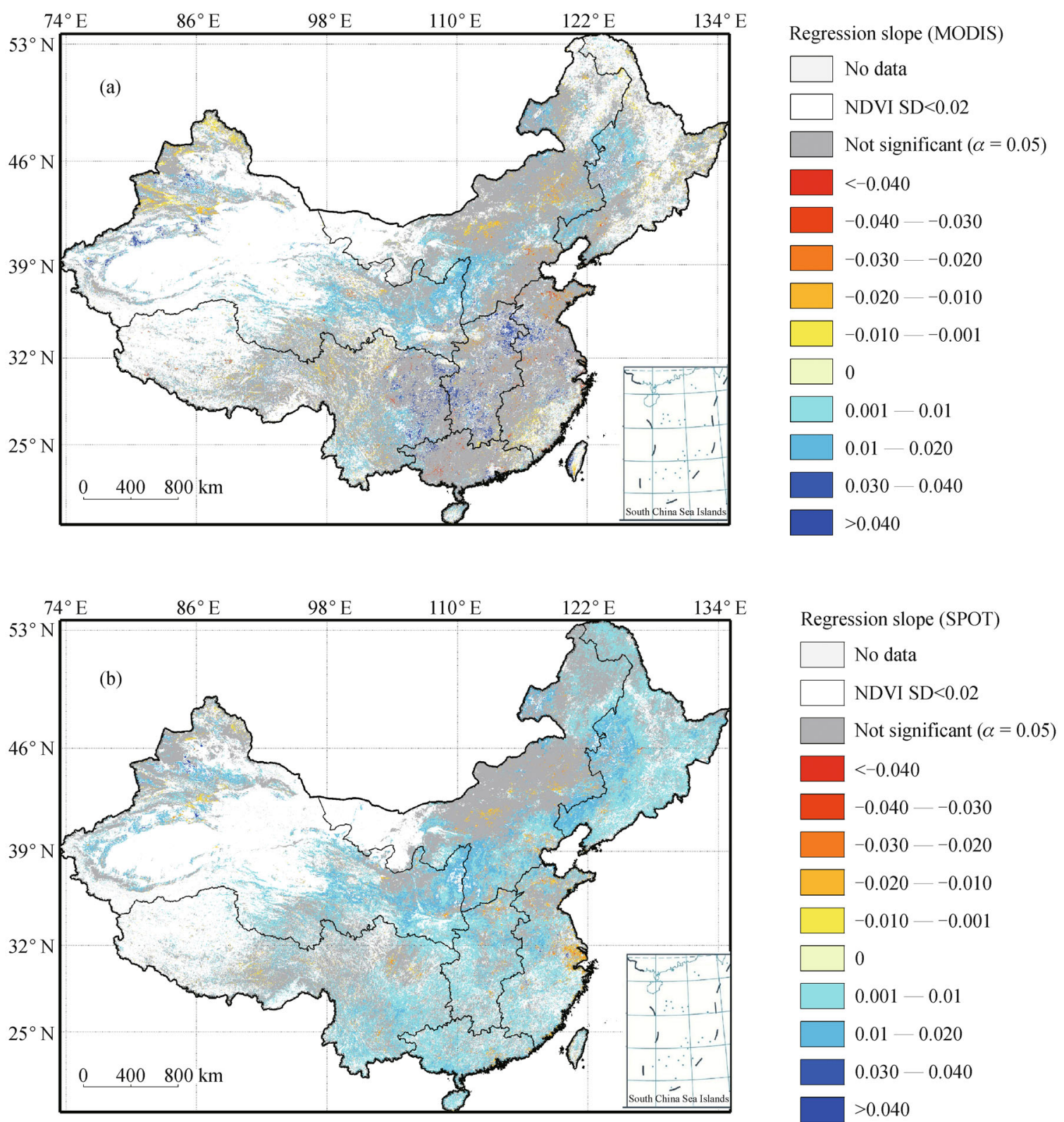

Fig. 2 Linear trend regression slope values of MODIS NDVI (a) and SPOT NDVI (b) from 2000 to 2011.

Northeast China (Changbai Mountain and Three-Rivers Plain). The trend is also noticeable in larger areas of Northwest China (both sides of the Tianshan Mountains), where a mixed pattern of positive/negative trends was generally observed in both datasets, with more negative trends observed in NDVI than in MODIS (4.9\% of MODIS and $1.7 \%$ of SPOT).

Based on the comparison of MODIS and SPOT NDVI trend slopes over all of China, the positive regression slopes were higher for SPOT NDVI data over the 12-year period. More pixels from SPOT have positive trends (53.2\%) than do pixels from the MODIS dataset (25.4\%). This finding is possibly caused by a change in the spectral response functions from SPOT VGT1 to SPOT VGT2 in
January 2003. Reflectance differences are due to calibration for the B2 (red band) and B3 (near-infrared). A reflectance bias of $2.1 \%$ and $6.3 \%$, and an increase in observed NDVI of $3.4 \%$ (NDVI > 0.3), were found (http:// www.vgt.vito.be/faqnew/index.html; refer to Question5.1).

Significant regression slope values from MODIS and SPOT NDVI observations show that for pixels with good agreement between the two datasets, scatter-plots should be located in the first and third quadrants (Fig. 3). A blue to red color change represents an increase in the density of the pixel (Fig. 3). In general, significant NDVI regression slope values of annual MODIS and SPOT data show a good agreement in China (almost in the first and third 

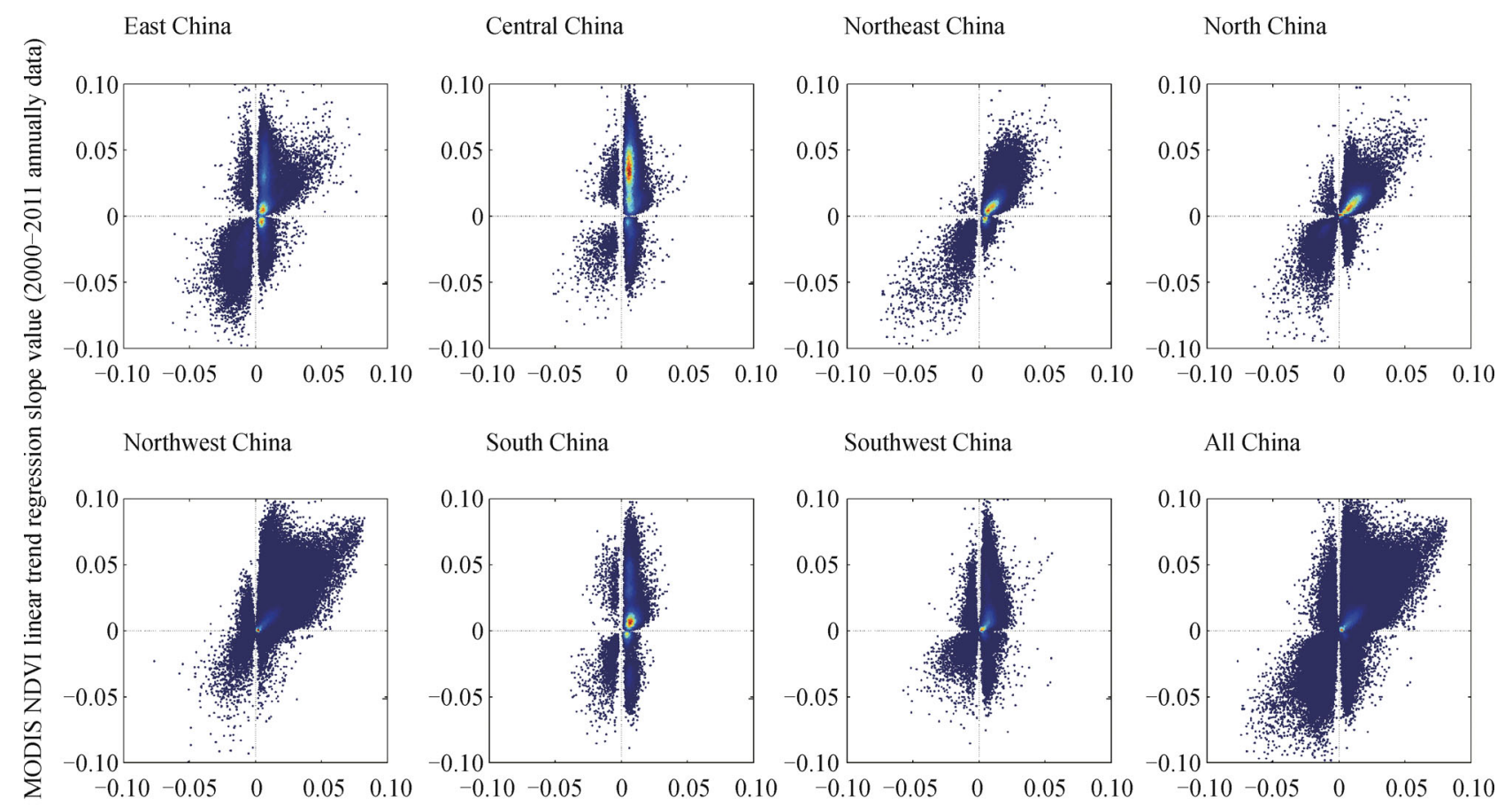

SPOT NDVI linear trend regression slope value (2000-2011 annually data)

Fig. 3 Density scatterplot of linear trend regression slope values of SPOT vs. MODIS NDVI (2000-2011 annual data; $\alpha=0.05)$.

Table 1 Trend statistics (per sub-region) for MODIS and SPOT NDVI linear trend analysis from 2000-2011 $(\alpha=0.05)$

\begin{tabular}{lcccccccc}
\hline Number of observations & E.China & C.China & NE.China & N.China & NW.China & S.China & SW.China & All China \\
\hline Total pixels $(n)$ MODIS NDVI SD $>0.02$ & 937,916 & 664,291 & $1,147,027$ & $2,099,090$ & $3,940,266$ & 537,742 & $2,738,140$ & $12,064,472$ \\
MODIS NDVI positive regression slope $(n)$ & 130,900 & 169,666 & 288,302 & 486,196 & $1,276,252$ & 71,906 & 636,236 & $3,059,458$ \\
MODIS NDVI negative regression slope $(n)$ & 79,233 & 22,815 & 123,044 & 127,527 & 194,193 & 36,092 & 178,423 & 761,327 \\
MODIS NDVI positive regression slope/\% & 14 & 25.5 & 25.1 & 23.2 & 32.4 & 13.4 & 23.2 & 25.4 \\
MODIS NDVI negative regression slope/\% & 8.4 & 3.4 & 10.7 & 6.1 & 4.9 & 6.7 & 6.5 & 6.3 \\
Total pixels $(n)$ SPOT NDVI SD $>0.02$ & 938,814 & 664,291 & $1,148,316$ & $2,099,369$ & $3,940,161$ & 538,559 & $2,739,452$ & $12,068,962$ \\
SPOT NDVI positive regression slope $(n)$ & 511,063 & 429,059 & 950,942 & 926,582 & $2,036,452$ & 357,842 & $1,207,722$ & $6,419,662$ \\
SPOT NDVI negative regression slope $(n)$ & 61,072 & 13,292 & 6,728 & 42,518 & 65,490 & 12,959 & 71,649 & 273,708 \\
SPOT NDVI positive regression slope/\% & 54.4 & 64.6 & 82.8 & 44.1 & 51.7 & 66.4 & 44.1 & 53.2 \\
SPOT NDVI negative regression slope/\% & 6.5 & 2 & 0.6 & 2 & 1.7 & 2.4 & 2.6 & 2.3 \\
\hline
\end{tabular}

quadrants). There is a correlation between NDVI regression slope values (almost in the first and third quadrants) for Northeast China, North China, and Northwest China, where there are more positive than negative trend pixels. For East China, Central China, South China, and Southwest China, the magnitude of the regression slope value varies, but most pixels are distributed in the first and third quadrants. In particular, the low MODIS data quality caused some data loss in Central China and South China, despite the temporal filter and the Savitsky-Golay methods used to improve data quality. However, the MODIS data did not change significantly with a confidence level of $95 \%$ in the study period (Fig. 3). Many pixels with positive regression slopes in SPOT and negative slopes in MODIS were observed in the fourth quadrant (Figs. 2(a) and 2(b)).

\subsection{Spatial patterns in annual MODIS vs. SPOT NDVI}

For areas with a high $r$ value, the mean regression slope value between MODIS and SPOT is expected to be closer to 1 . From linear regression trend analysis, regression slope values (Fig. 4(a)) and $r$ values (Fig. 4(b)) of annual observations of MODIS and SPOT NDVI (2000-2011) have better consistency in areas with slope values of 
Table 2 Trend statistics for MODIS and SPOT NDVI linear trend analysis from 2000-2011 $(\alpha=0.05)$ for major land cover classes

\begin{tabular}{|c|c|c|c|c|c|c|c|c|}
\hline \multirow[b]{2}{*}{ Land cover class } & MODIS $n$ & MODIS & MODIS & \multirow{2}{*}{$\begin{array}{l}\text { MODIS } \\
\text { regression } \\
\text { slope mean } \\
\quad \text { value }\end{array}$} & \multirow{2}{*}{$\begin{array}{l}\text { SPOT } n \\
(\alpha=0.05)\end{array}$} & \multirow{2}{*}{$\begin{array}{c}\text { SPOT } \\
n>0 / \%\end{array}$} & \multirow{2}{*}{$\begin{array}{c}\text { SPOT } \\
n<0 / \%\end{array}$} & \multirow{2}{*}{$\begin{array}{c}\text { SPOT } \\
\text { regression } \\
\text { slope mean } \\
\text { value }\end{array}$} \\
\hline & $(\alpha=0.05)$ & $n>0 / \%$ & $n<0 / \%$ & & & & & \\
\hline Evergreen needleleaf forest & 24,640 & 51.5 & 48.5 & 0.0043 & 47,180 & 89.5 & 10.5 & 0.0063 \\
\hline Evergreen broadleaf forest & 21,597 & 64.7 & 35.3 & 0.0055 & 94,201 & 99.6 & 0.4 & 0.0066 \\
\hline Deciduous needleleaf forest & 4,620 & 74.6 & 25.4 & 0.0033 & 31,809 & 99.9 & 0.1 & 0.0066 \\
\hline Deciduous broadleaf forest & 15,553 & 71.8 & 28.2 & 0.0058 & 101,390 & 100 & 0 & 0.006 \\
\hline Mixed forest & 149,902 & 73 & 27 & 0.0095 & 577,099 & 99.6 & 0.4 & 0.0066 \\
\hline Closed shrublands & 37,374 & 71.3 & 28.7 & 0.0062 & 57,603 & 85.6 & 14.4 & 0.006 \\
\hline Open shrublands & 64,983 & 86.9 & 13.1 & 0.0087 & 80,804 & 91.7 & 8.3 & 0.0068 \\
\hline Woody savannas & 185,333 & 85.9 & 14.1 & 0.0142 & 449,618 & 97.5 & 2.5 & 0.007 \\
\hline Savannas & 1,586 & 77.3 & 22.7 & 0.0076 & 2,820 & 95.1 & 4.9 & 0.0078 \\
\hline Grasslands & 673,470 & 82 & 18 & 0.0084 & 824,384 & 94.1 & 5.9 & 0.0092 \\
\hline Croplands & 516,652 & 85.3 & 14.7 & 0.0132 & $1,022,332$ & 95.9 & 4.1 & 0.0087 \\
\hline $\begin{array}{l}\text { Cropland/Natural vegetation } \\
\text { mosaic }\end{array}$ & 159,649 & 83.5 & 16.5 & 0.0133 & 411,699 & 97.2 & 2.8 & 0.0071 \\
\hline Barren or sparsely vegetated & 135,832 & 94.4 & 5.6 & 0.0086 & 183,285 & 96 & 4 & 0.0078 \\
\hline
\end{tabular}

Table 3 Statistics of the MODIS/SPOT NDVI linear trend regression slope value $(\mathrm{p}<0.05)$ for major land cover classes from $2000-2011$

\begin{tabular}{lccc}
\hline Land cover class & $n$ & $n(p<0.05) / \%$ & Regression slope mean value \\
\hline Evergreen needleleaf forest & 110,815 & 22.7 & 0.48 \\
Evergreen broadleaf forest & 81,336 & 21.7 & 0.44 \\
Deciduous needleleaf forest & 21,600 & 30 & 0.81 \\
Deciduous broadleaf forest & 46,654 & 36.9 & 0.53 \\
Mixed forest & 560,421 & 30.1 & 0.48 \\
Closed shrublands & 122,502 & 35.8 & 0.62 \\
Open shrublands & 175,151 & 53.7 & 0.81 \\
Woody savannas & 622,734 & 30.4 & 0.46 \\
Savannas & 3,407 & 50.7 & 0.73 \\
Grasslands & $2,021,034$ & 72.3 & 0.9 \\
Croplands & $1,552,034$ & 45.5 & 0.69 \\
Cropland/Natural vegetation mosaic & 565,520 & 30.5 & 0.53 \\
Barren or sparsely vegetated & 220,836 & 71.8 & 0.86 \\
All classes & $6,104,044$ & 50.2 & 0.64
\end{tabular}

approximately 1 (between 0.9 and 1.1). The regions with high $r$ values (between 0.9 and 1) were found in northern China, including Northeast China, North China, and Northwest China. In East China, Central China, South China, and Southwest China, regression slope values for MODIS and the linear correlation of MODIS and SPOT NDVI data are low. The spatial differences of the regression slope (Fig. 6(a)) and $r$ values (Fig. 6(b)) in MODIS and SPOT NDVI can also be observed in the corresponding standard deviation difference map (Fig. 6(c)). There are no significant changes $(p<0.05)$ in most areas for the regression slope (Fig. 4(a)) and $r$ values
(Fig. 4(b)), which corresponds to the large area of positive differences in the MODIS and SPOT standard deviation, especially on the border of East China and Central China. Positive and negative trends can be seen in the regression slope map of MODIS and SPOT NDVI linear trend (Figs. 2(a) and 2(b)).

When plotting density scatterplots (per sub-region) of the MODIS/SPOT $(\alpha=0.05)$ linear regression slope values against the $r$ values from linear regression trend analysis of annual observations of MODIS and SPOT NDVI (20002011) (Fig. 5), the majority of the pixels' correlation and slope values between MODIS and SPOT NDVI show 


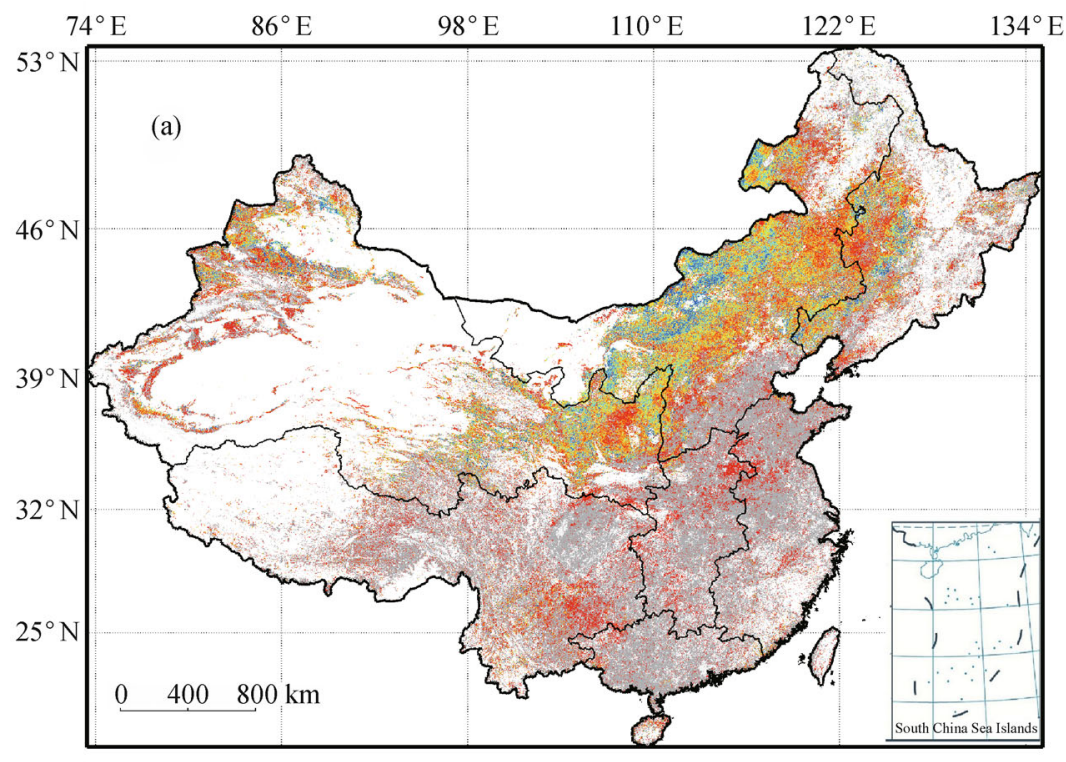

Regression slope (MODIS/SPOT)
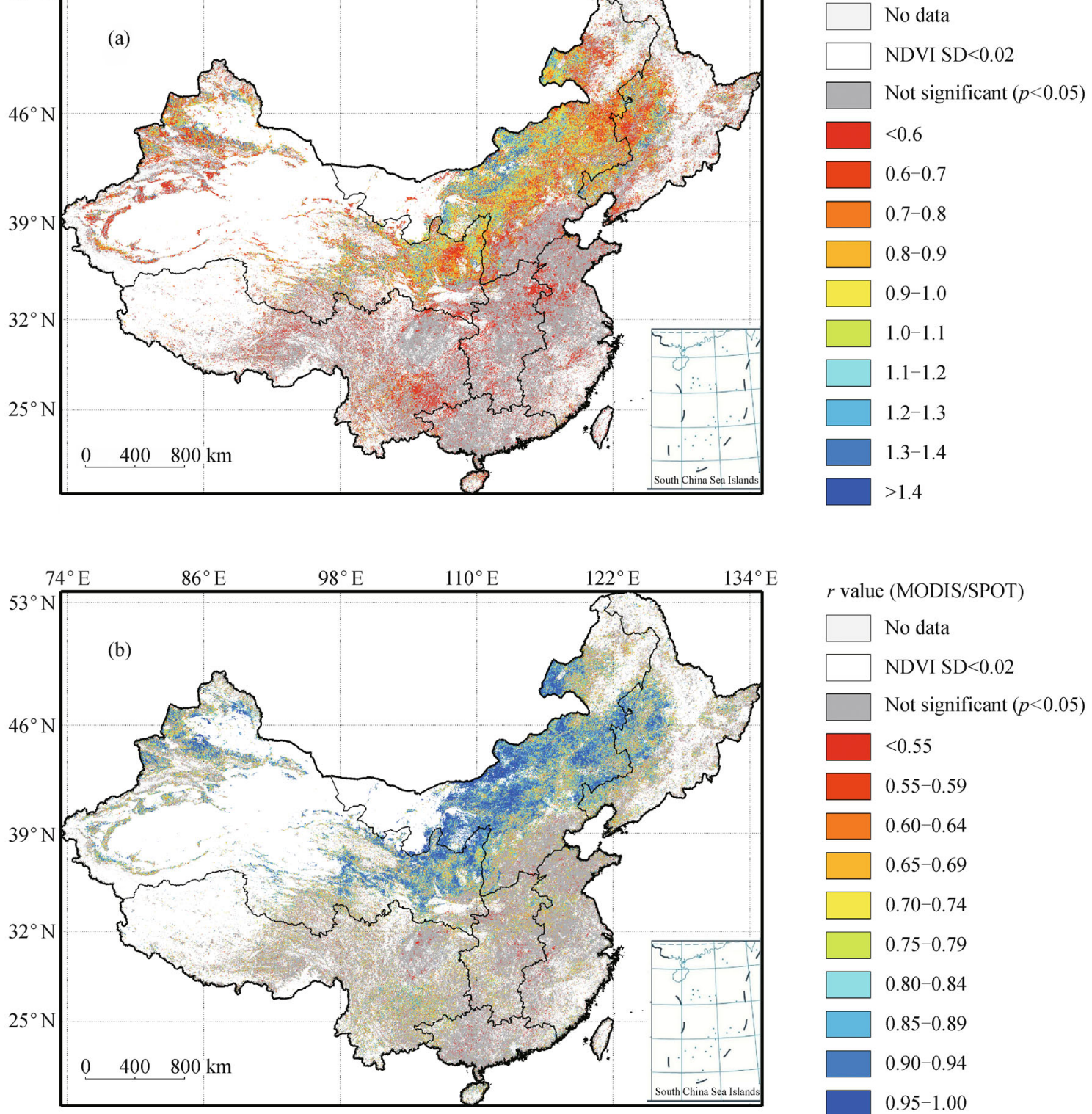

Fig. 4 Regression slope values (a) and $r$-values (b) from linear regression trend analysis of annual observations of MODIS and SPOT NDVI from 2000-2011.

differences in the seven regions of China. In Northeast China, North China, and Northwest China, there are a large number of pixels with high $r$ values and slope values close to 1 , especially in North China. This finding could be explained by lesser amount of cloud cover experienced in this region. In East China, Central China, and South China, a large number of pixels have low $r(0.6-0.75)$ and slope values $(<0.5)$. The same trend was found in Southwest China, with low $r(0.6-0.75)$ and slope values $(\sim 0.5)$. This result could be attributed to the region's seasonal variation, greater precipitation, more cloud cover, and vegetation growth. However, there is good agreement in the regression slope and $r$ values throughout the country. Song et al. (2010) obtained higher correlations in northern China than in southern China between data from the SPOT VGT and GIMMS NDVI; in addition, Fensholt and Proud (2012) found similar results between the MODIS and GIMMS NDVI.

\subsection{Differences between annual MODIS and SPOT NDVI}

Differences were calculated by the MODIS NDVI dataset 
minus the SPOT NDVI. Positive differences indicate that the MODIS NDVI is more positive for each pixel than is the SPOT NDVI. The significant spatial differences in regression slope values in East China, Central China, Southwest China, and South China (blue color) become apparent from the spatial distribution of the difference between MODIS and SPOT NDVI (Fig. 6(a)). The large positive differences in the MODIS and SPOT NDVI correlate with the regions with low regression slope values shown in Fig. 2(b) and Fig. 4(a) (also visible in Figs. 3 and 5). The apparent regression slope difference is in agreement with the land cover class "Croplands" (Fig. 1 ). There is a significant difference (red $<-0.8$ and blue $>0.8$ ) in Northeast China, the southern part of North China, East China, Central China, and South China between MODIS and SPOT NDVI $r$ values due to the opposing direction of trends (also visible in Figs. 4(b) and 5). The land cover in these areas is a mix of "Evergreen needleleaf forest," "Evergreen broadleaf forest," "Deciduous needleleaf forest," "Deciduous broadleaf forest," and "Mixed forest" (Fig. 1). The standard deviation difference reflects the degree of dispersion between the two NDVI datasets. Large areas with a positive standard deviation difference are mainly distributed in the southern part of North China, East China, Central China, South China, and Southwest China. Most of these areas are in agreement with the land cover class "Croplands" (Fig. 1). Addition- ally, small areas of negative standard deviation differences are distributed in Northwest China. This result can partially be explained by the corresponding slope value difference (Fig. 6(a)), $r$ value difference (Fig. 6(b)), and $r$ value (Fig. 4(b)). Conversely, large areas with high standard deviation differences correspond to the relatively small values of the regression slopes (Fig. 4(a)).

Due to the differences between the two datasets, especially in the southern regions of China, explanations need to be drawn for the varying slope, $r$ value, and standard deviation. This result can be explained by the fact that NDVI tends to saturate at the dense vegetation (Sellers, 1985; Gao et al., 2000; Fensholt et al., 2009), especially in the humid areas of southern China that can experience a large amount of cloud cover (Zhang et al., 2006). The temporal filter algorithms used in this study had an additional impact on the data (Fensholt et al., 2009).

\subsection{Influence of land cover classes on MODIS and SPOT NDVI trends}

Table 2 summarizes the number of pixels, the increased and decreased rates of pixels, the regression slope mean values, and the major land cover classes for the MODIS and SPOT NDVI linear trend analysis from 2000 to 2011 $(\alpha=0.05)$. The MODIS NDVI slope showed an increasing trend mainly in the "Open shrublands," "Woody savan-
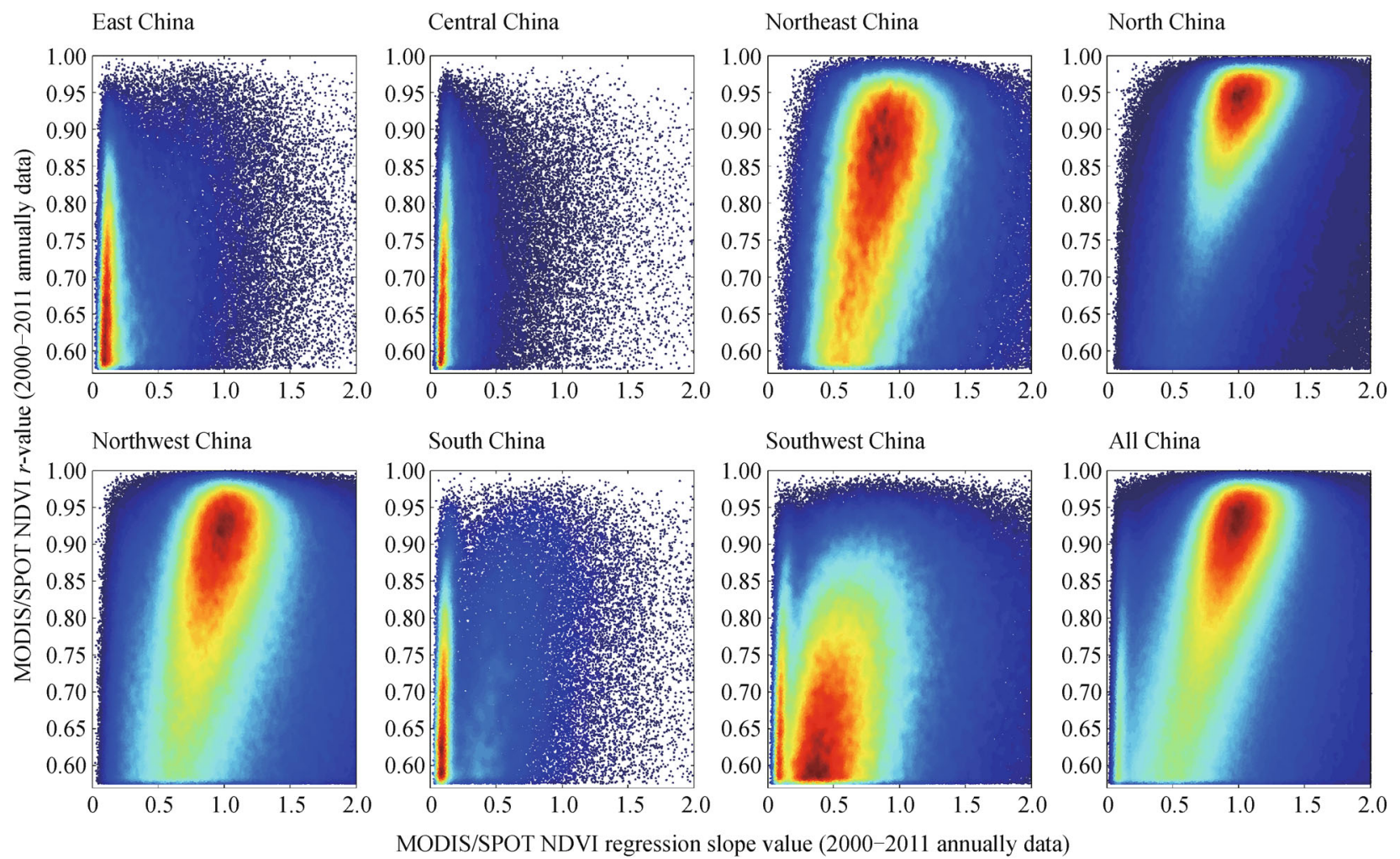

Fig. 5 Density scatterplot of regression slope vs. $r$-values from linear regression trend analysis of annual observations of MODIS and SPOT NDVI from 2000-2011. 


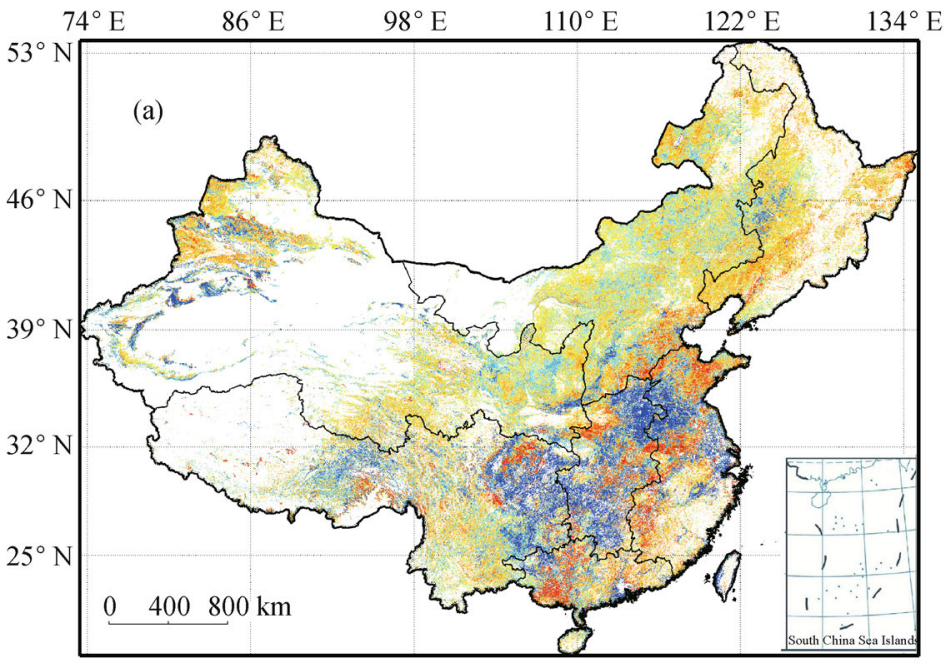

Regression slope difference (NDVI)
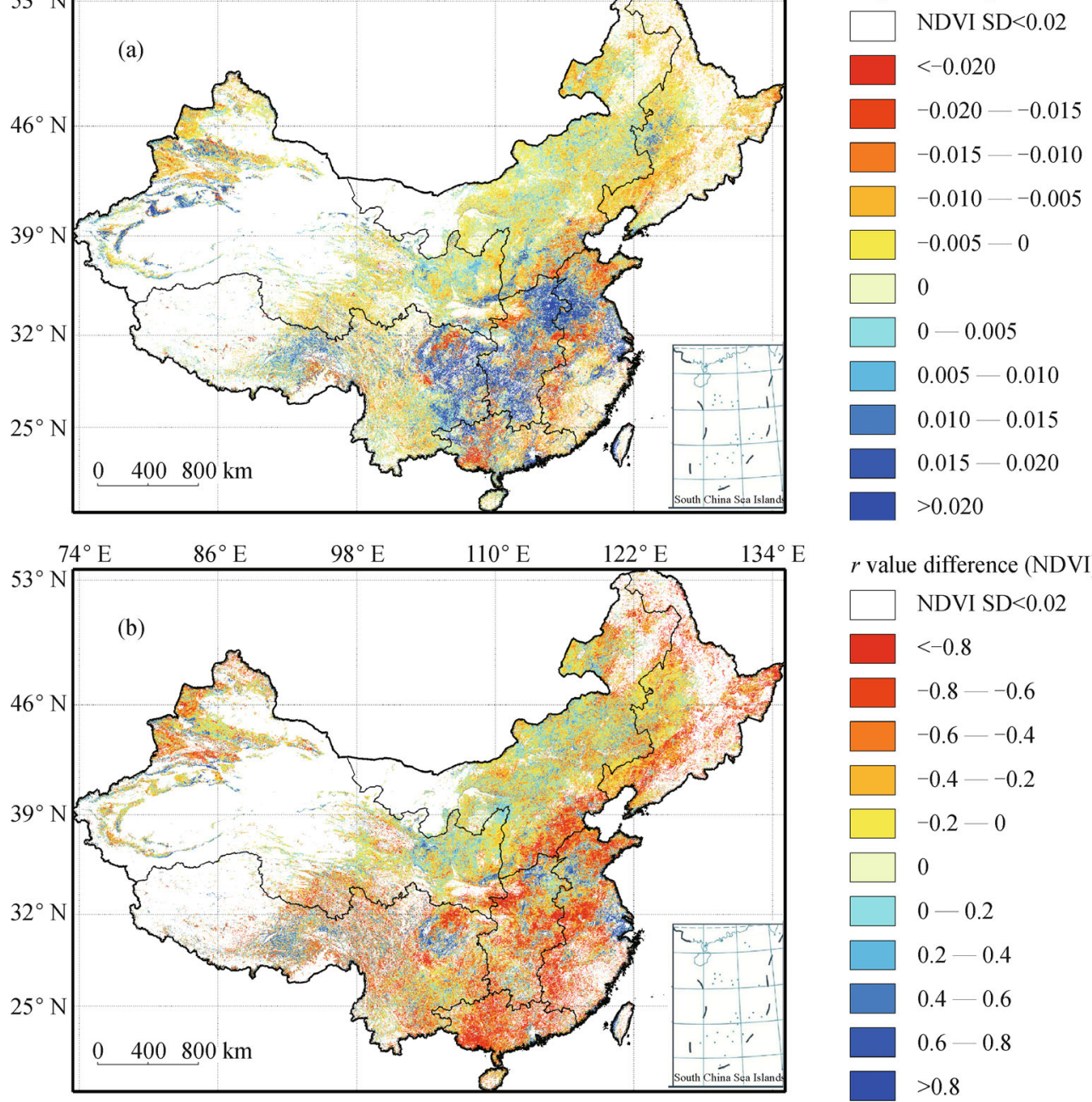

$r$ value difference (NDVI)
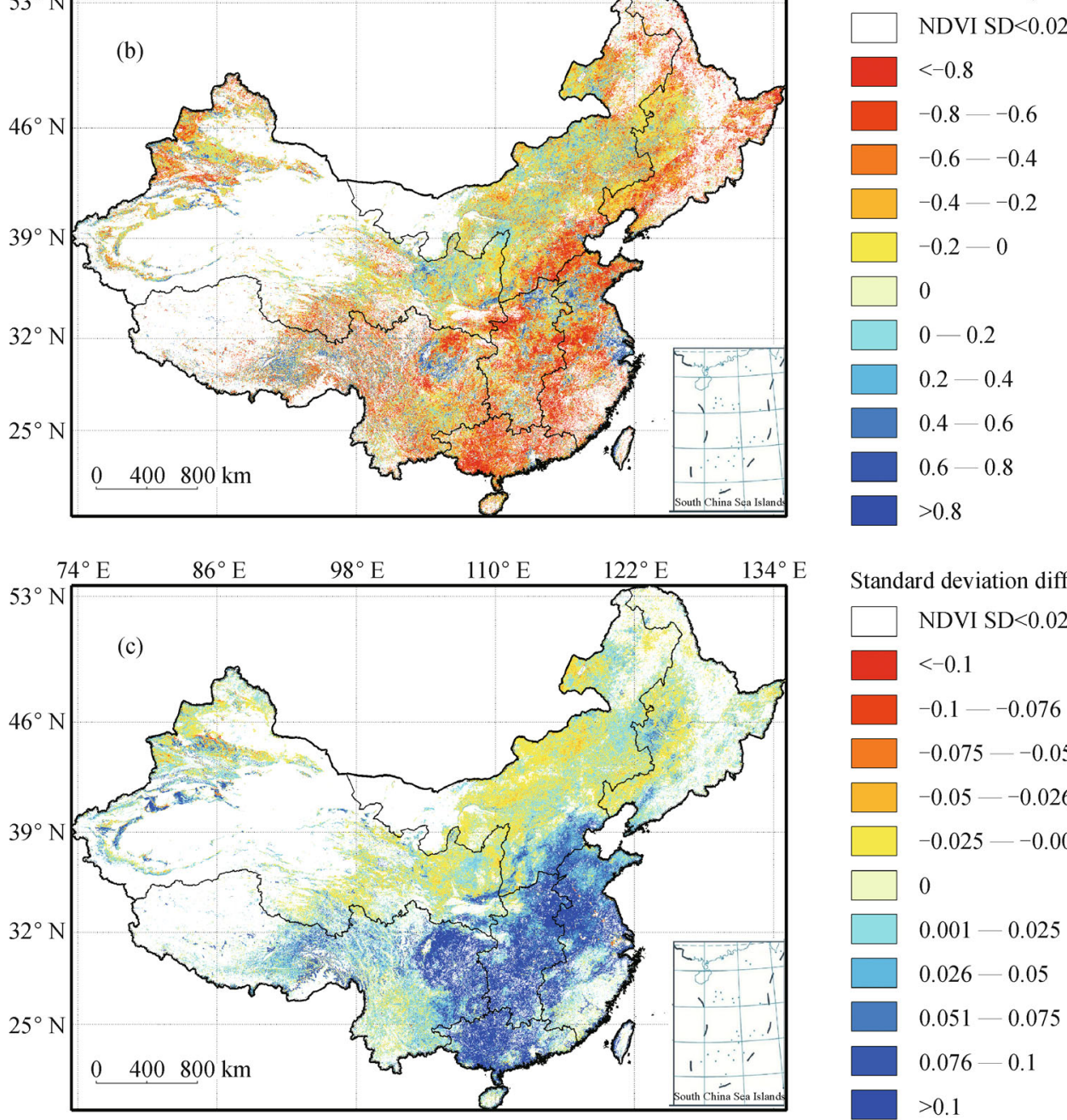

Standard deviation difference (NDVI)

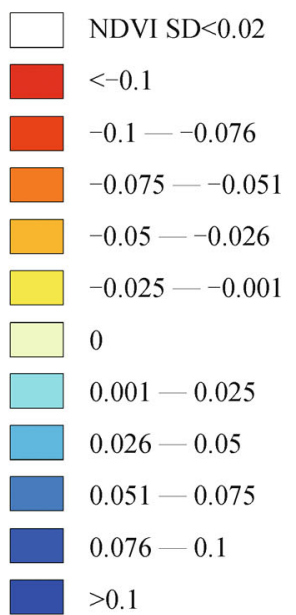

Fig. 6 Differences in regression slope (a), $r$-values (b), and annual standard deviation difference (c) between MODIS and SPOT NDVI, respectively (2000-2011 annual observations). 
nas," "Grasslands," "Croplands," "Cropland/Natural vegetation mosaic," and "Barren or sparsely vegetated." The SPOT NDVI slope for most of the land cover classes showed an increasing trend greater than $90 \%$ (Table 2). When comparing the MODIS and SPOT NDVI regression slope mean value, the greatest difference of the four forest types ("Evergreen needleleaf forest," "Evergreen broadleaf forest," "Deciduous needleleaf forest," and "Deciduous broadleaf forest") was generally less than for SPOT NDVI and varied greatly. This analysis showed that MODIS NDVI easily saturates for the forest, while the SPOT NDVI can better detect the forest vegetation (Sellers, 1985; Gao et al., 2000; Fensholt et al., 2009). Similar results can also be found in Figs. 2(a) and 2(b).

The change in the regression slope mean value for "Open shrublands," "Grasslands," and "Barren or sparsely vegetated" was relatively greater over the 12 years (Table 3). Areas of three types of vegetation cover shown in Fig. 4 (a) and Table 2 show the same results for the regression slope value. MODIS and SPOT NDVI were consistent for these vegetation covers, primarily found in arid and semiarid regions due to the smaller NDVI values. However, the two datasets show a relatively good consistency for all vegetation data.

\section{Conclusions}

The Terra MODIS and SPOT VGT NDVI datasets are the most widely used in recent years for long-term monitoring of vegetation changes. The consistency of the data between Terra MODIS and SPOT VGT NDVI datasets with a $1-\mathrm{km}$ spatial resolution was evaluated using a linear regression method. This study indicated that comparisons between the Terra MODIS and SPOT VGT NDVI for an overlapping period of 12 years in China have a high rate of agreement for northern China. In southern China, the SPOT VGT NDVI data had more positive regression slope values than did the Terra MODIS data at a confidence level of $95 \%$ using the non-parametric Mann-Kendall (MK) method. This analysis suggests that Terra MODIS and SPOT VGT NDVI datasets have a relatively robust basis for characterizing vegetation changes in annual NDVI in most of the semi-arid and arid areas in northern China. Differences between the two datasets suggest that trends in the southern regions of China should be carefully interpreted.

\footnotetext{
Acknowledgements This paper was supported by the Key Research Program of the Chinese Academy of Sciences (Grant No. KZZD-EW-14), the National Natural Science Foundation of China (Grant Nos. 41171334 and 41071278), Ecological Innovation \& Breeding Project (Y254021031,355031061), USDA NIFA Project (2010-34263-21075), the Research Fund for the Doctoral Program of Higher Education (20100076120024), and the Fundamental Research Funds for the Central Universities (East China Normal University), Ministry of Education. The authors thank the NASA/MODIS Land Discipline Group and Spot Image/
}

Vito for producing and sharing the MODIS LAND and SPOT VEGETATION data. We extend these thanks to Yuan Zhang for his assistance in reviewing the English version of this paper. We want to acknowledge suggestions from the anonymous reviewers, which helped to improve this manuscript.

\section{References}

Bai Z G, Dent D L, Olsson L, Schaepman M E (2008). Proxy global assessment of land degradation. Soil Use Manage, 24(3): 223234

Bartalev S A, Belward A S, Erchov D V, Isaev A S (2003). A new SPOT4-VEGETATION derived land cover map of Northern Eurasia. Int J Remote Sens, 24(9): 1977-1982

Beck H E, McVicar T R, van Dijk A I J M, Schellekens J, de Jeu R A M, Bruijnzeel L A (2011). Global evaluation of four AVHRR-NDVI data sets: intercomparison and assessment against Landsat imagery. Remote Sens Environ, 115(10): 2547-2563

Fensholt R, Nielsen T T, Stisen S (2006). Evaluation of AVHRR PAL and GIMMS 10-day composite NDVI time series products using SPOT-4 vegetation data for the African continent. Int J Remote Sens, 27(13): 2719-2733

Fensholt R, Proud S R (2012). Evaluation of Earth Observation based global long term vegetation trends - Comparing GIMMS and MODIS global NDVI time series. Remote Sens Environ, 119: 131147

Fensholt R, Rasmussen K, Nielsen T T, Mbow C (2009). Evaluation of earth observation based long term vegetation trends - Intercomparing NDVI time series trend analysis consistency of Sahel from AVHRR GIMMS, Terra MODIS and SPOT VGT data. Remote Sens Environ, 113(9): 1886-1898

Gao X, Huete A R, Ni W, Miura T (2000). Optical-biophysical relationships of vegetation spectra without background contamination. Remote Sens Environ, 74(3): 609-620

Heumann B W, Seaquist J, Eklundh L, Jönsson P (2007). AVHRR derived phenological change in the Sahel and Soudan, Africa, 19822005. Remote Sens Environ, 108(4): 385-392

Hickler T, Eklundh L, Seaquist J W, Smith B, Ardö J, Olsson L, Sykes M T, Sjöström M (2005). Precipitation controls Sahel greening trend. Geophys Res Lett, 32(21): L21415

Hu M Q, Mao F, Sun H, Hou Y Y (2011). Study of normalized difference vegetation index variation and its correlation with climate factors in the three-river-source region. Int J Appl Earth Observ Geoinf, 13(1): 24-33

Huete A, Didan K, Miura T, Rodriguez E P, Gao X, Ferreira L G (2002). Overview of the radiometric and biophysical performance of the MODIS vegetation indices. Remote Sens Environ, 83(1-2): 195-213 Lucht W, Prentice I C, Myneni R B, Sitch S, Friedlingstein P, Cramer W, Bousquet P, Buermann W, Smith B (2002). Climatic control of the high-latitude vegetation greening trend and Pinatubo effect. Science, 296(5573): 1687-1689

Maisongrande P, Duchemin B, Dedieu G (2004). VEGETATION/SPOT: an operational mission for the Earth monitoring; presentation of new standard products. Int J Remote Sens, 25(1): 9-14

Mao D H, Wang Z M, Luo L, Ren C Y (2012). Integrating AVHRR and MODIS data to monitor NDVI changes and their relationships with 
climatic parameters in Northeast China. Int J Appl Earth Observ Geoinf, 18: 528-536

Mildrexler D J, Zhao M, Running S W (2009). Testing a MODIS Global Disturbance Index across North America. Remote Sens Environ, 113 (10): 2103-2117

Nemani R R, Keeling C D, Hashimoto H, Jolly W M, Piper S C, Tucker C J, Myneni R B, Running S W (2003). Climate-driven increases in global terrestrial net primary production from 1982 to 1999 . Science, 300(5625): 1560-1563

Pettorelli N, Vik J O, Mysterud A, Gaillard J M, Tucker C J, Stenseth N C (2005). Using the satellite-derived NDVI to assess ecological responses to environmental change. Trends Ecol Evol, 20(9): 503510

Rahman H, Dedieu G (1994). SMAC: a simplified method for the atmospheric correction of satellite measurements in the solar spectrum. Int J Remote Sens, 15(1): 123-143

Savitzky A, Golay M J E (1964). Smoothing and differentiation of data by simplified least squares procedure. Anal Chem, 36(8): 1627-1639

Schowengerdt R A (2007). Remote sensing: models and methods for image processing (3rd ed). San Diego: Academic press, 19-20

Sellers P J (1985). Canopy reflectance, photosynthesis and transpiration. Int J Remote Sens, 6(8): 1335-1372

Song Y, Ma M, Veroustraete F (2010). Comparison and conversion of AVHRR GIMMS and SPOT VEGETATION NDVI data in China. Int J Remote Sens, 31(9): 2377-2392

Stöckli R, Vidale P L (2004). European plant phenology and climate as seen in a 20-year AVHRR land-surface parameter dataset. Int $\mathrm{J}$ Remote Sens, 25(17): 3303-3330

Symeonakis E, Drake N (2004). Monitoring desertification and land degradation over sub-Saharan Africa. Int J Remote Sens, 25(3): 573592

Tucker C J (1979). Red and photographic infrared linear combinations for monitoring vegetation. Remote Sens Environ, 8(2): 127-150

Tucker C J, Slayback D A, Pinzon J E, Los S O, Myneni R B, Taylor M G (2001). Higher northern latitude normalized difference vegetation index and growing season trends from 1982 to 1999. Int J Biometeorol, 45(4): 184-190

Wang Q, Adiku S, Tenhunen J, Granier A (2005). On the relationship of NDVI with leaf area index in a deciduous forest site. Remote Sens Environ, 94(2): 244-255

Wolfe R E, Nishihama M, Fleig A J, Kuyper J A, Roy D P, Storey J C, Patt F S (2002). Achieving sub-pixel geolocation accuracy in support of MODIS land science. Remote Sens Environ, 83(1-2): 31-49

Xiao X, Braswell B, Zhang Q, Boles S, Frolking S, Moore B III (2003). Sensitivity of vegetation indices to atmospheric aerosols: continentalscale observations in Northern Asia. Remote Sens Environ, 84(3): 385-392

Zhang X, Friedl M A, Schaaf C B (2006). Global vegetation phenology from Moderate Resolution Imaging Spectroradiometer (MODIS): evaluation of global patterns and comparison with in situ measurements. J Geophys Res, 111 (G4): G04017

\section{AUTHOR BIOGRAPHIES}

Youzhi An received his M.S. degree from Shanghai Normal University, Shanghai, China, in 2011. He is currently a Ph.D student in the Department of Geography at East China Normal University, Shanghai, China. His current research interests focus on remote sensing of vegetation ecology. E-mail: anyouzhi@163.com

Wei Gao is a senior research scientist and director of the USDA UVB Monitoring and Research Program and the Center of Remote Sensing and Modeling for Agricultural Sustainability, Natural Resource Ecology Laboratory, Colorado State University. He is also a joint professor with the Department of Soil and Crop Sciences, Colorado State University. He received his $\mathrm{Ph} . \mathrm{D}$ from Purdue University and did his Postdoctoral training at the National Center for Atmospheric Research. His research interests include atmospheric radiation and modeling, remote sensing applications, regional climate/ecosystem modeling, geographic information systems, UV radiation, and other climate stress factor influences on ecosystems and their impact on climate change. He has published numerous academic papers and edited numerous books, scientific proceedings, and special journal issues. He is a fellow of the International Society for Optical Engineering (SPIE). E-mail: wgao419@gmail.com

Zhiqiang Gao received his Ph.D from the Institute of Remote Sensing Applications, Chinese Academy of Sciences, Beijing, China in 1998. His major field of study is Cartography and Geographical Information Systems. He studied and worked at the Chinese Academy of Sciences for 19 years. His research includes applications of remote sensing, geographical information systems, land use/ land cover cartography, ecosystem modeling, impacts of UV-B on crops using an eco-model, and applications for coupling of field (insitu). He has published 102 scientific papers, owns 8 software copyrights, 2 patents, and 4 books. E-mail: gaoland@gmail.com

Chaoshun Liu received his Ph.D in atmospheric remote sensing science and technology from Nanjing University of Information Science and Technology in 2008. He has since been employed at the East China Normal University. His research involves atmospheric radiation and modeling, surface energy flux and terrestrial remote sensing, aerosol retrieval and climate effects, calibration and atmospheric correction, and other atmospheric parameter retrievals. E-mail: csliu@re.ecnu.edu.cn

Runhe Shi is an Associate Professor in the Department of Geography at East China Normal University, China. He is working at the Key Laboratory of Geographic Information Science, Ministry of Education, China, and serves as an Assistant Director. He obtained his B.S. in Geography from East China Normal University in 2001 and Ph.D in Cartography and Geographic Information Systems from the Institute of Geographic Sciences and Natural Resources Research, Chinese Academy of Sciences, in 2006. His primary area of research is quantitative remote sensing including retrieval of plant biochemistry, greenhouse gases, and particulate matters in the atmosphere. He has authored more than 50 refereed journal articles and conference papers. He is also the holder of two patents for data processing of remote sensing images. E-mail: shirunhe@gmail.com 